\title{
Highly Selective Oxidation of Methane to Methanol at Ambient Conditions by Titanium Dioxide-supported Iron Species
}

Jijia Xie ${ }^{1}$, Renxi Jin², Ang $\mathrm{Li}^{3}$, Yingpu Bi ${ }^{4}$, Qiushi Ruan ${ }^{1}$, Yucheng Deng ${ }^{2}$, Yajun Zhang ${ }^{4}$,

Siyu $\mathrm{Yao}^{2}$, Gopinathan Sankar ${ }^{5}$, Ding $\mathrm{Ma}^{2 *} \&$ Junwang Tang ${ }^{1 *}$

1. Department of Chemical Engineering, University College London, London WC1E 7JE, United Kingdom.

2. College of Chemistry and Molecular Engineering and College of Engineering, BIC-ESAT, Peking University, Beijing 100871, P. R. China

3. Beijing Key Laboratory of Microstructure and Property of Advanced Materials, Beijing University of Technology, Beijing, 100024, China

4. State Key Laboratory for Oxo Synthesis \& Selective Oxidation, National Engineering Research Center for Fine Petrochemical Intermediates, Lanzhou Institute of Chemical Physics, Chinese Academy of Sciences, Lanzhou 730000, China

5. Department of Chemistry, University College London, London WC1H OAJ, United Kingdom.

\begin{abstract}
Methane activation at moderate conditions and with good selectivity for value-added chemicals still remains a huge challenge. Here, we present a highly selective catalyst for the transformation of methane to methanol composed of highly dispersed iron species on $\mathrm{TiO}_{2}$. The catalyst operates under moderate light irradiation (close to one sun) and at ambient conditions. The optimised sample shows a $15 \%$ conversion rate for $\mathrm{CH}_{4}$ with an alcohol selectivity of over $97 \%$ (methanol selectivity over $90 \%$ ) and a yield of 18 moles of alcohol per mole of iron active site in just three hours. XPS measurements with and without Xenon lamp irradiation, light intensity-modulated spectroscopies, photoelectrochemical measurements, XANES and EXAFS spectra, as well as isotopic analysis confirm the function of the major ironcontaining species, namely $\mathrm{FeOOH}$ and $\mathrm{Fe}_{2} \mathrm{O}_{3}$, which enhance charge transfer and separation, decrease the overpotential of the reduction reaction and improves selectivity towards methanol over $\mathrm{CO}_{2}$ production.
\end{abstract}




\section{Introduction}

The ongoing discovery of large reserves of shale gas and fire ice, points to methane - their major component - as a potential alternative to crude oil, not only as an energy vector but also as a chemical feedstock. ${ }^{1,2}$ However, due to the high stability of the $\mathrm{C}-\mathrm{H}$ bonds, the negligible electron affinity, and the low polarizability, a multi-step catalytic transformation first to syngas under high temperatures and pressures is normally required in industrial processes for methane transformation. Consequently, methane activation is energy- and $\mathrm{CO}_{2}$ emissionintensive. Reducing the reaction temperature and/or pressure while maintaining a high catalytic performance would save an enormous amount of capital investment, running cost and mitigate safety and environmental concerns. ${ }^{3}$

The preferable product of methane conversion is methanol which can be directly used in fuel cells. ${ }^{4}$ However, this process is not favourable under ambient conditions due to the extremely large activation energy requirement. Homogeneous catalysts that have been reported to catalyse methane oxidation to methanol, such as $\mathrm{Hg}^{5} \mathrm{Pt}^{6-8}$ and $\mathrm{Pd}^{9-11}$ complexes, in most cases operate at high pressure (20-70 bar), in strongly acidic media (e.g. oleum) or relatively high temperature (up to $500 \mathrm{~K}$ ). Meanwhile, a few heterogeneous catalysts have been reported, such as $\mathrm{Fe}^{12-15}$ and $\mathrm{Cu}^{15-20}$ anchored on zeolites but most of them were only active at relatively high temperatures (400-800 K) and high pressures (20-40 bar). In some cases, pre-oxidation of active sites was also required, which is likely to increase the intricacy of the process. ${ }^{10-20}$ Very recently, two efficient reaction pathways of direct methane conversion to methanol were just published. ${ }^{21,22}$ Hutchings et al. ${ }^{21}$ converted $\mathrm{CH}_{4}$ to methanol using a $\mathrm{PdAu}$ catalyst in the presence of $\mathrm{H}_{2} \mathrm{O}_{2}$ and $\mathrm{O}_{2}$, working at moderate reaction conditions of 30 bar and $50^{\circ} \mathrm{C}$, resulting in methanol selectivity of ca. $45 \%$ (total organic compounds selectivity of $92 \%) .{ }^{21}$ Flytzani-Stephanopoulos et al. ${ }^{22}$ further discovered a Rh-based catalyst that converts $\mathrm{CH}_{4}$ to methanol with much higher selectivity in the presence of $\sim 27$ bar of gas mixture and at $150^{\circ} \mathrm{C}$.

One can see that either high temperature and/or high pressure is still crucial for efficient $\mathrm{CH}_{4}$ activation, while low temperature is preferred in order to avoid over-oxidation of methanol to $\mathrm{CO}$ or $\mathrm{CO}_{2 .}{ }^{21}$ This dilemma remains an important challenge for methane conversion to methanol. Photocatalysis is a technology that utilises photons instead of high temperature to drive chemical reactions at ambient conditions ( 1 bar and ca. room temperature), ${ }^{23-25}$ and has been widely used in small molecule activation, such as for water, ${ }^{26-28}$ nitrogen ${ }^{29,30}$ and $\mathrm{CO}_{2 .}{ }^{31-}$ 33 All of these reactions are well-known as thermodynamically nonspontaneous and are challenging to achieve under mild conditions by thermal catalytic processes. Thus, 
photocatalysis could provide an alternative approach to drive the selective conversion of methane to thermodynamically unstable products, e.g. methanol.

Despite such potential, there are few reports of photocatalytic processes for $\mathrm{CH}_{4}$ transformation under ambient conditions and with satisfactory selectivity for methanol production. ${ }^{34-37}$ Herein we report metal oxide species anchored on $\mathrm{TiO}_{2}$ as a photon promoted catalysts for methane conversion to methanol in the presence of $\mathrm{H}_{2} \mathrm{O}_{2}$ at room temperature and 1 bar gas pressure. Furthermore, we show that iron oxide species are the most active for this process compared with other noble metals or transition metal clusters. Interestingly, a selectivity of over $90 \%$ for methanol with no $\mathrm{CO}$ as side product was achieved with $0.33 \mathrm{wt} \%$ $\mathrm{FeO}_{x} / \mathrm{TiO}_{2}$.

\section{Results}

Photocatalytic partial oxidation of methane

The metal co-catalysts were loaded onto anatase $\mathrm{TiO}_{2}$ by a rapid and facile impregnation method. The structure and chemical states of these catalysts were investigated by X-ray photoelectron spectroscopy (XPS) and X-Ray Diffraction (XRD) as shown in Supplementary Figures 1-7. ${ }^{38-43}$ Clearly, after loading these metals, $\mathrm{TiO}_{2}$ retains the anatase structure while the diffraction patterns associated with the metals are not observed, indicating that the metal species are highly dispersed over the surface of the $\mathrm{TiO}_{2}$, and can be resolved by the X-ray photoelectron spectra (XPS) instead. Importantly the XPS (Supplementary Figures 5 and 6) show that the interaction between the small iron species and $\mathrm{TiO}_{2}$ is the strongest among all the analysed metal- $\mathrm{TiO}_{2}$ catalysts. This is likely due to a match in Fermi levels, as well as the high dispersity and small size of the nanoclusters. The metal loading was calculated from inductively coupled plasma-atomic emission spectrometry (ICP-AES) measurements and was between 0.12 wt.\% and 1.09 wt.\%. Bare $\mathrm{TiO}_{2}$ samples and those loaded with various metals were then evaluated for the methane photo-oxidation reaction with hydrogen peroxide as an oxidant (methane/hydrogen peroxide ratio $=8.75: 1$ ). Bare $\mathrm{TiO}_{2}$ showed a methane conversion rate of $10.9 \%$ over 3 hours of light irradiation but with low selectivity for methanol (36\%) (Figure 1a and b and Supplementary Figure 8). Clearly, the introduction of different metals has a major impact on the catalytic performance. For samples with noble metal catalysts, such as 0.12 metalwt.\% $\mathrm{Au} / \mathrm{TiO}_{2}, 0.53$ metalwt.\% $\mathrm{PdO} \times / \mathrm{TiO}_{2}$, and 0.69 wt.\% $\mathrm{PtO} / \mathrm{TiO}$, a drastic drop in both methane conversion and methanol selectivity is observed, with the main product being $\mathrm{CO}_{2}$ (Supplementary Figure 8). This is consistent with a previous report of $\mathrm{CH}_{4}$ oxidation to $\mathrm{CO}_{2}$ by a noble metal loaded $\mathrm{ZnO}$ photocatalyst. ${ }^{37}$ When dispersing $0.33 \mathrm{wt} \%$ iron species over $\mathrm{TiO}_{2}$, the catalyst presents not only much better methane conversion but also enhanced 
selectivity for methanol when compared with the other samples. The iron species decorated sample exhibits a 1.5 fold increase in $\mathrm{CH}_{4}$ conversion and a ca. 4 fold enhancement in methanol production over bare $\mathrm{TiO}_{2}$, despite the larger surface area of the latter (Supplementary Table 1).

We further studied the effect of the iron oxide species loading amount on the catalytic performance. Both $\mathrm{CH}_{4}$ conversion and the selectivity towards methanol are affected by the amount of the iron species while following the same trends. For example, as shown in Figure 1c, at hour 2 , the conversion rate on 0.13 metalwt.\% $\mathrm{FeO}_{x} / \mathrm{TiO}_{2}$ is $11.24 \%$, on 0.33 metalWt.\% $\mathrm{FeO}_{x} / \mathrm{TiO}_{2}$ is $14.9 \%$, on 0.78 metalwt.\% $\mathrm{FeO}_{x} / \mathrm{TiO}_{2}$ is $13.0 \%$ and on 1.12 metalwt.\% $\mathrm{FeO}_{x} / \mathrm{TiO}_{2}$ is $12.1 \%$. Methanol production follows the same trend (Figure 1c and d). Such a change is believed to be due to more iron oxide species facilitating charge separation, scattering photons and obstructing light absorption of the $\mathrm{TiO}_{2}$. The methanol selectivity on 0.33 metalwt.\% $\mathrm{FeO}_{\times} / \mathrm{TiO}_{2}$ is the highest at $90 \%$ and the yield is also the highest at $1056 \mathrm{umol} / \mathrm{g}_{\mathrm{cat}}$ (or 18 moles of methanol per mole of iron) after 3 hours, which is about five times higher than reported very recently by thermal catalysis within the similar reaction time (e.g. $\sim 3$ $\mathrm{mol} / \mathrm{mol}_{\text {metal }}{ }^{21}$ and $\sim 3.9 \mathrm{~mol} / \mathrm{mol}_{\mathrm{Rh}}{ }^{22}$ ). Furthermore, the photocatalytic route operates in much more moderate experimental conditions (ambient conditions). The methanol production on bare $\mathrm{TiO}_{2}$ and on the 0.13 metalWt.\% iron species decorated sample decreases after the initial stage due to the over-oxidation of methanol to $\mathrm{CO}_{2}$ as shown in Supplementary Figure 9. ${ }^{28}$ Furthermore, the $\mathrm{H}_{2} \mathrm{O}_{2}$ amount is important for controlling the selectivity for methanol as shown in Supplementary Figure 10. When no $\mathrm{H}_{2} \mathrm{O}_{2}$ is present, no $\mathrm{CH}_{4}$ is converted. Increasing $\mathrm{H}_{2} \mathrm{O}_{2}$ increases $\mathrm{CH}_{4}$ conversion but the selectivity for methanol decreases. The optimal ratio of $\mathrm{H}_{2} \mathrm{O}_{2}$ to $\mathrm{CH}_{4}$ is 0.11 . 

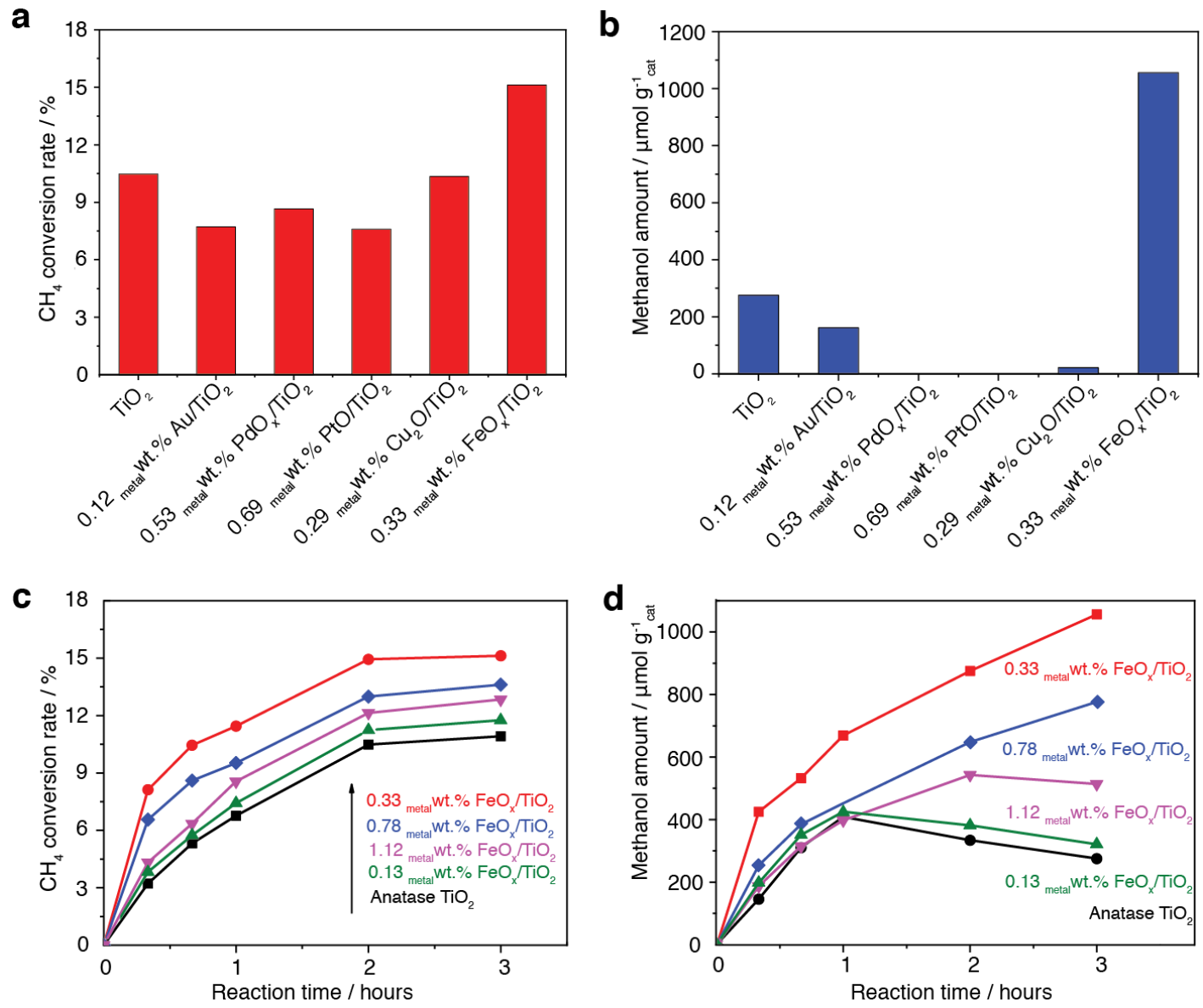

Figure 1: Photocatalytic methane conversion under different conditions. (a) Methane conversion rates and (b) methanol yield on a series of metal modified $\mathrm{TiO}_{2}$ samples during 3-hour full arc irradiation; (c) time-on-line methane

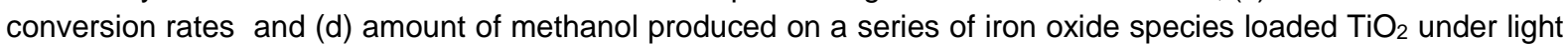
irradiation by using $10 \mathrm{mg}$ photocatalysts, $70 \mu \mathrm{mol} \mathrm{CH}_{4}$ in argon, $8 \mu \mathrm{mol} \mathrm{H}_{2} \mathrm{O}_{2}$ in $10 \mathrm{ml}$ water operated at room temperature and atmospheric pressure.

Figure 2a presents the stability of the best sample 0.33 metalwt.\% $\mathrm{FeO}_{\mathrm{x}} / \mathrm{TiO}_{2}$. Between each run, the catalysts were dried at $70^{\circ} \mathrm{C}$ in order to evaporate all absorbed reactants and products. The catalyst presents a similar methane conversion rate and methanol evolution rate across 3 runs. The iron species before and after the stability tests were characterised by XPS as shown in Supplementary Figure 11 and there is no visible change of the chemical state of the iron species in 0.33 metalwt.\% $\mathrm{FeO}_{x} / \mathrm{TiO}_{2}$, indicating good stability of the catalyst during the redox reaction. The major by-product is ethanol with ca. $7 \%$ selectivity, leading to $97 \%$ in total for alcohols (methanol and ethanol). $\mathrm{CO}_{2}$ is produced with $3 \%$ selectivity and very importantly there is no $\mathrm{CO}$ produced, indicating a very clean methanol fuel. Control experiments are presented in Figure $2 \mathrm{~b}$. Firstly, under dark conditions, the 0.33 metalwt. $\% \mathrm{FeO}_{x} / \mathrm{TiO}_{2}$ catalyst shows very little methane conversion and only a trace amount of methanol is formed, indicating that the reaction between methane and hydrogen peroxide is possible but with a very slow reaction rate. For catalysts without $\mathrm{TiO}_{2}$, for example, 0.41 metalwt.\% $\mathrm{FeO} \times\left(\mathrm{SiO}_{2}\right.$, where $\mathrm{SiO}_{2}$ cannot be excited by Xenon lamp irradiation, ${ }^{28,44}$ the formation of a small amount 
of methanol and carbon dioxide is possibly due to the photo-Fenton reaction. ${ }^{45,46}$ We also conducted a control experiment without methane and did not observe any products. Further control experiments in the absence of any photocatalyst were carried out (Supplementary Figure 12), exhibiting a very low $\mathrm{CH}_{4}$ conversion rate of $1.85 \%$ and a very low selectivity of $17 \%$ towards methanol, consistent with previous reports. ${ }^{47}$ As shown in Supplementary Figure 13 , the homogeneous photo-Fenton process has also been carried out by using $0.6 \mu \mathrm{mol}$ $\mathrm{FeCl}_{2}$, which shows a similar activity and selectivity for methanol formation to that without iron ions, due to limited $\cdot \mathrm{OH}$ radicals generated in the absence of a light absorber $\left(\mathrm{TiO}_{2}\right)$ and no far-UV $(<300 \mathrm{~nm})$ in the light spectrum, as shown in Supplementary Figure 14. Hence, all methanol detected is from methane conversion in the presence of light, $\mathrm{TiO}_{2}$ and iron species. In other words, it is clear that the photocatalysis process by 0.33 metalwt.\% $\mathrm{FeO}_{x} / \mathrm{TiO}_{2}$ is the major contribution to methane conversion. In order to further prove methanol is generated from methane, isotope labelling was conducted by using the same amount of ${ }^{12} \mathrm{CH}_{4}$ or ${ }^{13} \mathrm{CH}_{4}$ as a reactant as shown in Figures $2 c$ and $2 d$. The peak at $m / z=32$ is the strongest and stronger than reported in the database (NIST MS 229809) owing to the strong baseline signal from $\mathrm{O}_{2}$ $\left(\mathrm{O}_{2}+\mathrm{q}^{+} \rightarrow \mathrm{O}_{2}^{+}\right)$and unreacted $\mathrm{H}_{2} \mathrm{O}_{2}\left(\mathrm{O}_{2}^{2-}+\mathrm{q}^{+} \rightarrow \mathrm{O}_{2}^{-}\right) \cdot{ }^{48}$ Obviously, as shown in Figure $2 \mathrm{~d}$, when the reactant is replaced by ${ }^{13} \mathrm{CH}_{4}$, a new peak at $\mathrm{m} / \mathrm{z}=33$ is present indicating the generation of ${ }^{13} \mathrm{CH}_{3} \mathrm{OH}^{+}$. Consistently two peaks at $m / z=29$ and $m / z=30$ in Figure $2 \mathrm{c}$ also shift to the higher mass-charge ratio of $m / z=30$ and $m / z=31$ (Figure $2 d$ ) with constant relative intensity. Thus, the methanol generated is from methane conversion driven by photocatalysis. 
a

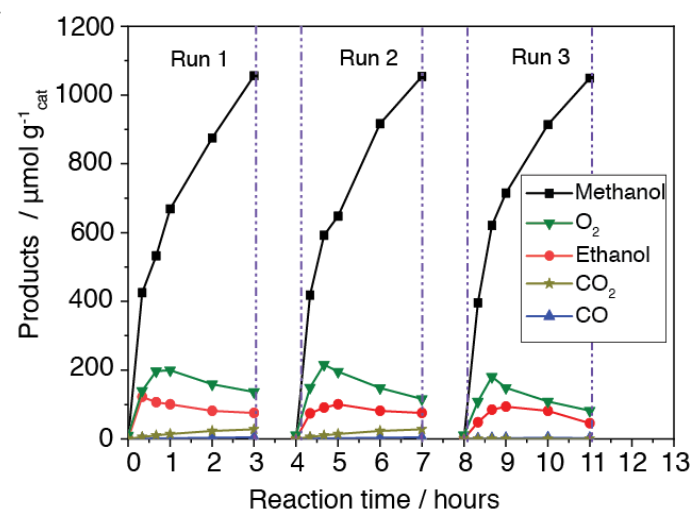

C

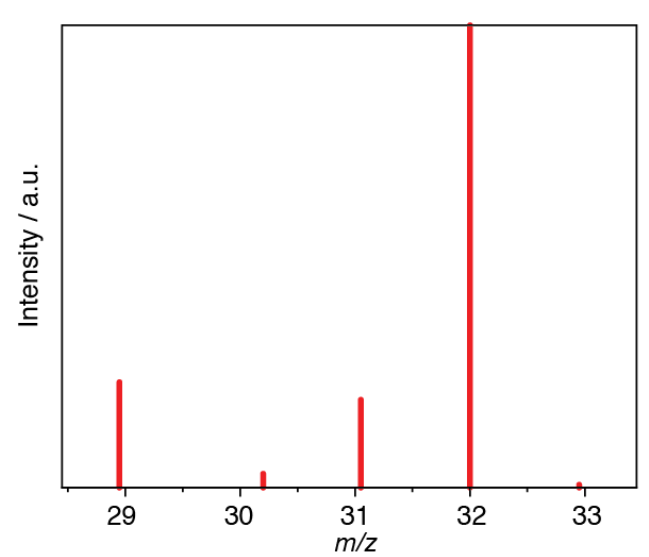

b

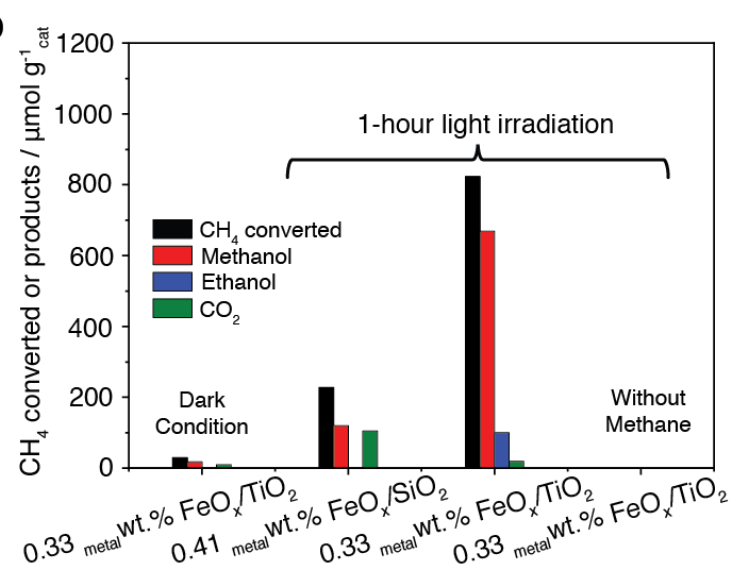

d

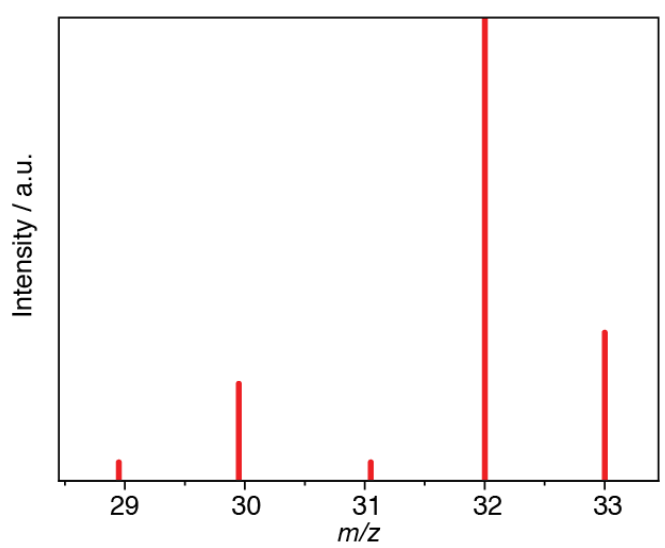

Figure 2: Stabliliyt of photocatalysts and carbon source identification during $\mathrm{CH}_{4}$ transformation. (a) Three runs of $\mathrm{CH}_{4}$ conversion by 0.33 metalwt.\% $\mathrm{FeO}_{x} / \mathrm{TiO}_{2}$ under light irradiation operated at room temperature and atmospheric pressure; (b) methane conversion amount and product yield of a series of control experiments; (c) mass spectrum $(\mathrm{m} / \mathrm{z}=29-33)$ of liquid products after $30 \mathrm{~min}$ light irradiation by using $10 \mathrm{mg} 0.33 \mathrm{wt} \% \mathrm{FeO} \times / \mathrm{TiO}_{2}$ catalyst and 70 $\mu \mathrm{mol}{ }^{12} \mathrm{CH}_{4}$ in argon and (d) isotope labelled mass spectrum $(\mathrm{m} / \mathrm{z}=29-33)$ of liquid products under the same conditions while using $70 \mu \mathrm{mol}{ }^{13} \mathrm{CH}_{4}$.

Characterisations of the optimised sample 0.33 wt.\% $\mathrm{FeO}_{x} / \mathrm{TiO}_{2}$

The morphology of 0.33 metalwt.\% $\mathrm{FeO}_{x} / \mathrm{TiO}_{2}$ was investigated by transmission electron microscopy (TEM) as shown in Supplementary Figure 15. The $\mathrm{TiO}_{2}$ particles have an average diameter of ca. $20 \mathrm{~nm}$. Under scanning transmission electron microscopy (STEM), as shown in Figure $3 \mathrm{a}$, highly dispersed iron species on $\mathrm{TiO}_{2}$ are resolved, inclulding very small clusters and even atomically dispersed species. Some ca. $2 \mathrm{~nm}$ particles were also observed as shown in Supplementary Figure 16 might owing to the intense electron beam during TEM test or agglomeration during sample synthesis. When increasing the Fe loading amount to 0.78 wt.\% and 1.12 wt.\%, clearly much larger $\alpha-\mathrm{Fe}_{2} \mathrm{O}_{3}$ particles (20 to $200 \mathrm{~nm}$ ) can be observed (Supplementary Figure 17 and 18). Therefore, $0.33 \mathrm{wt} . \%$ is the optimal concentration to form highly dispersed iron species catalyst on $\mathrm{TiO}_{2}$. 
The chemical states of iron species on the best catalyst $\left(0.33\right.$ metalwt.\% $\left.\mathrm{FeO} \times / \mathrm{TiO}_{2}\right)$ were characterised by XPS (Figure 3b). The main peaks located at ca.710 eV and $725 \mathrm{eV}$ are associated with the Fe $2 p 3 / 2$ and Fe $2 p 1 / 2$, respectively. ${ }^{49-51}$ They can be further fitted with six peaks as shown in Figure 3b. Two peaks located at $710 \mathrm{eV}$ and $724 \mathrm{eV}$ are associated with an $\mathrm{Fe}$ (III) oxidation state. ${ }^{49-51}$ The satellite peaks at $719 \mathrm{eV}$ and $728 \mathrm{eV}$ are also the fingerprint of an $\mathrm{Fe}$ (III) oxidation state. ${ }^{49-51}$ The additional peaks at $714 \mathrm{eV}$ and $726 \mathrm{eV}$ are related to the effects of hydroxide groups. ${ }^{49,51}$ The chemical states of the iron species were further confirmed by X-ray near edge structure (XANES) spectroscopies. As shown in Figure $3 \mathrm{c}$, the Fe K-edge shifts to higher energy with the increase of iron valence state (from Fe metal, $\mathrm{FeO}, \mathrm{Fe}_{3} \mathrm{O}_{4}$ to $\mathrm{Fe}_{2} \mathrm{O}_{3}, \mathrm{Fe}(\mathrm{OH})_{3}$ and $\left.\mathrm{FeOOH}\right)$. The position of the Fe K-edge spectrum of 0.33 metalwt.\% $\mathrm{FeO}_{\times} / \mathrm{TiO}_{2}$ is very similar to both $\mathrm{FeOOH}$ and $\mathrm{Fe}_{2} \mathrm{O}_{3}$, indicating that the oxidation state of the iron species in the catalyst is close to +3 valence with a distorted octahedral symmetry. The detailed XANES comparison between four Fe(III)-containing standards and 0.33 metalwt.\% $\mathrm{FeO}_{x} / \mathrm{TiO}_{2}$ are presented in Supplementary Figure 19. However, there is some feature in our sample which does not appear in these standards, thus the linear combination fitting (LCF) of XANES were conducted to further confirm the iron species. As shown in Supplementary Figure 19, the XANES of four Fe(III) standard compounds $\left(\alpha-\mathrm{Fe}_{2} \mathrm{O}_{3}, \gamma-\mathrm{Fe}_{2} \mathrm{O}_{3}\right.$, $\mathrm{FeOOH}$ and $\mathrm{Fe}(\mathrm{OH})_{3}$ ) are presented. As shown in Supplementary Table 2 and Supplementary Figure 20, the $\mathrm{Fe}$ species are most similar to $\mathrm{FeOOH}$, but $\mathrm{Fe}_{2} \mathrm{O}_{3}$ is also a necessary component. This is also in part proved by the Fe K-edge XANES results in Figure 3c. However, the low quality factors indicate that at least one more state other than these $\mathrm{Fe}(\mathrm{III})$-containing compounds presents. The STEM characterisation confirms that the extra state is likely due to the highly dispersion (even atomically dispersed species) of iron species. Thus, the majority Fe species are likely $\mathrm{FeOOH}$ and then $\mathrm{Fe}_{2} \mathrm{O}_{3}$, which is also consistent with the XPS results shown in Figure $3 b$ of two major kinds of $\mathrm{Fe}(\mathrm{III})$ species.

Figure 3d and Supplementary Figure 21 present the Fourier transform (FT) of the Fe K-edge extended X-ray absorption fine structure (EXAFS) of 0.33 wt. \% $\mathrm{FeO}_{x} / \mathrm{TiO}_{2}$. The peak at ca. $1.5 \AA$ (phase-shift not corrected) is assigned to the first oxygen neighbours around $\mathrm{Fe}^{3+}$ ions based on a detailed analysis of the EXAFS data. The fitting between experimental and calculated FT's along with their respective imaginary part of the FT are shown in Table 1. The analysis shown here indeed includes a contribution of $\mathrm{Fe}-\mathrm{Fe}$ (or $\mathrm{Ti}$ ) from the second neighbour correlation (see also Supplementary Figures 22 and 23). The low coordination number of Fe$\mathrm{Fe}(\mathrm{Ti})$ is owing to the small size of the iron species as shown in Figure $3 \mathrm{a}^{52}$ Both Fe K-edge XANES edge position and the Fe-O distance determined from analysis of EXAFS data indeed confirm that the iron in our catalyst is in the small cluster (or even atomically dispersed species) 
with a valence state of +3 (including $\mathrm{FeOOH}$ and $\mathrm{Fe}_{2} \mathrm{O}_{3}$ ), consistent with the observation of both TEM and XPS (Figures $3 a$ and $3 b$ ).

a

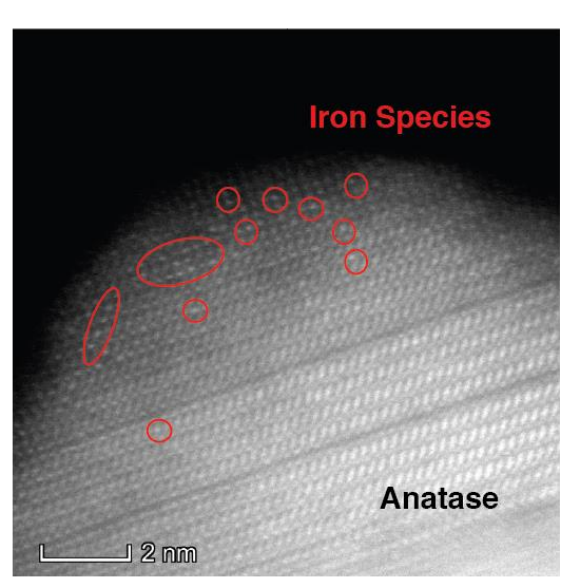

C

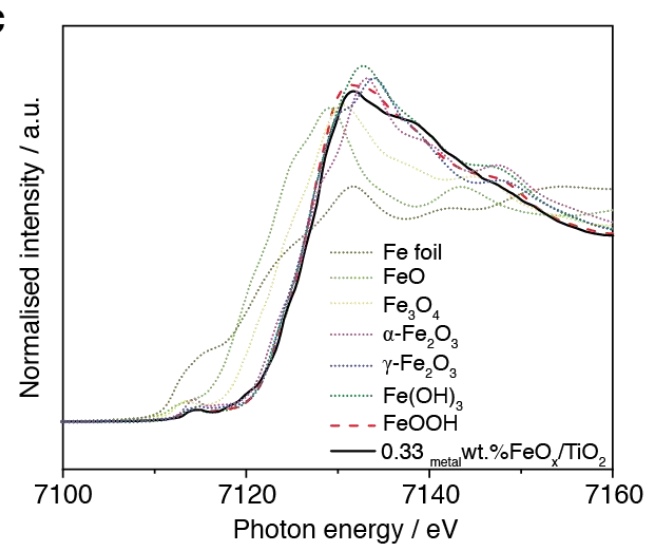

b

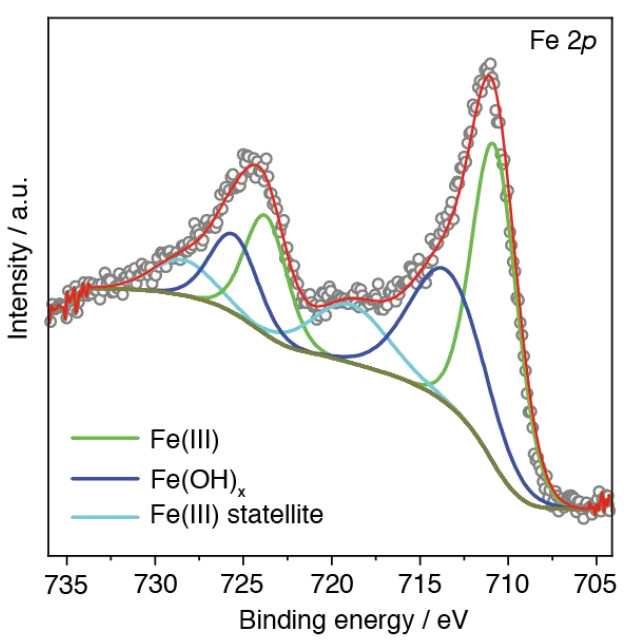

d

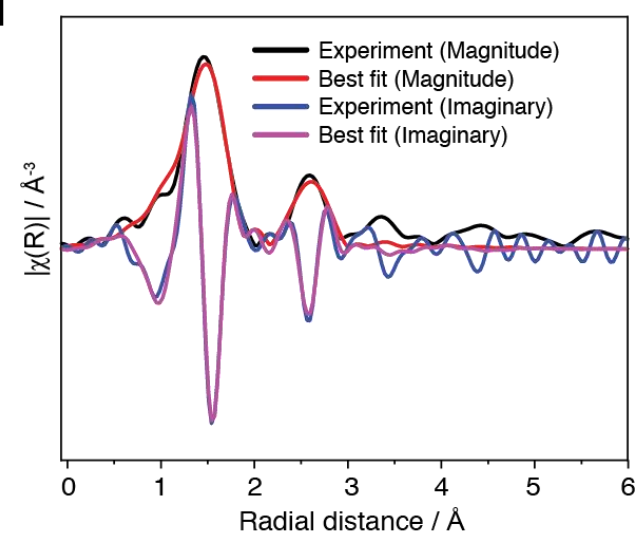

Figure 3: Physical observation of the 0.33 metalwt.\% $\mathrm{FeO}_{x} / \mathrm{TiO}_{2}$ sample. (a) STEM image and (b) Fe $2 p$ XPS spectra ; (c) Fe K-edge XANES results of $\mathrm{Fe}$ (metal), $\mathrm{FeO}, \mathrm{Fe}_{3} \mathrm{O}_{4}, \mathrm{FeOOH}, \mathrm{Fe}(\mathrm{OH})_{3}, \mathrm{Fe}_{2} \mathrm{O}_{3}$ and 0.33 metalwt.\% $\mathrm{FeO}_{x} \mathrm{TiO}_{2}$ and (d) fitting details for Fe K-edge EXAFS spectra of 0.33 metalwt.\% $\mathrm{FeO}_{\times} / \mathrm{TiO}_{2}$.

Table 1: Fitting results of Fe K-edge EXAFS spectra of 0.33 metalwt.\% $\mathrm{FeO}_{x} / \mathrm{TiO}_{2}$

\begin{tabular}{|c|c|c|c|c|c|}
\hline Shell & Bond length $(\dot{A})$ & Coordination number & E0 shift $(\mathrm{eV})$ & $\sigma^{2}\left(\AA^{2}\right)$ & R-factor \\
\hline $\mathrm{Fe}-\mathrm{O}$ & $1.97+/-0.01$ & $6.2+/-0.6$ & \multirow{2}{*}{-0.98} & $0.008+/-0.002$ & \multirow{2}{*}{0.0147} \\
\hline $\mathrm{Fe}-\mathrm{Fe}$ & $3.02+/-0.01$ & $2.9+/-0.2$ & & $0.012+/-0.005$ & \multirow{2}{*}{} \\
\hline
\end{tabular}

$\sigma^{2}:$ mean squared displacement;

The amplitude reduction factor is 0.816

\section{Discussion}

The function of the iron species was further investigated. The ultraviolet-visible (UV-Vis) spectra of $\mathrm{TiO}_{2}$ and the 0.33 metalwt.\% $\mathrm{FeO} \times / \mathrm{TiO}_{2}$ catalyst present similar ultraviolet light absorption abilities (Supplementary Figure 24). Figure 4a shows the photoluminescence (PL) spectroscopies of anatase $\mathrm{TiO}_{2}$ and 0.33 metalwt.\% $\mathrm{FeO}_{\times} / \mathrm{TiO}_{2}$. The PL intensity of the 0.33 metalwt.\% $\mathrm{FeO} \times / / \mathrm{TiO}_{2}$ sample is 10 times weaker than pure anatase $\mathrm{TiO}_{2}$, indicating a dramatic 
mitigation of charge recombination by the surface decoration. ${ }^{53,54}$ Intensity-modulated photocurrent spectroscopy (IMPS) and intensity-modulated photovoltage spectroscopy (IMVS) measurements as shown in Supplementary Figures 25 and 26 also suggest better charge separation by iron decoration. ${ }^{55-58} 0.33$ metalwt.\% $\mathrm{FeO}_{\times} / \mathrm{TiO}_{2}$ has a charge collection efficiency of $98 \%$, which is almost double that of bare $\mathrm{TiO}_{2}$, indicating dramatically enhanced charge transfer and separation. ${ }^{55}$

The X-ray photoelectron spectra of the Fe $2 p$ shell in samples in the presence and absence of Xenon lamp irradiation are shown in Figure $4 b$, which were used to confirm the electron transfer pathway. Acting as either an electron or hole acceptor, charge transfer occurring on iron species would change the binding energy of the Fe $2 p$ signal. ${ }^{59,60}$ According to Figure $4 b$, during Xe lamp irradiation, both $\mathrm{Fe} 2 p 3 / 2$ and $\mathrm{Fe} 2 p 1 / 2$ peaks shift to lower binding energy, which unambiguously indicates a reduced Fe species induced by light irradiation. Thus, the iron species work as an electron acceptor during the photocatalytic $\mathrm{CH}_{4}$ conversion process. The $\mathrm{O} 1 \mathrm{~s}$ peak shift to higher binding energy (Supplementary Figures 27 \& 28) further confirms the electron transfer pathway during light irradiation. The electrons are excited from the valence band (O $2 p$ orbitals) of $\mathrm{TiO}_{2}$ to the conduction band ( $\mathrm{Ti} 3 d$ orbits) and then transfer to the iron species, leaving holes on the oxygen atoms, which subsequently exhibit a higher binding energy.

A comparison of the reduction potentials of $\mathrm{H}_{2} \mathrm{O}_{2}$ on pure anatase and 0.33 metalwt.\% $\mathrm{FeO} \times{ }_{x} / \mathrm{TiO}_{2}$ was investigated on fluorine-doped tin oxide (FTO) glass electrodes as shown in Figure 4c. The onset potential of $\mathrm{H}_{2} \mathrm{O}_{2}$ reduction shifts positively by coating $\mathrm{TiO}_{2}$ on $\mathrm{FTO}$ due to the photocatalytic effect. It further shifts when introducing iron species on $\mathrm{TiO}_{2}$ indicating $\mathrm{H}_{2} \mathrm{O}_{2}$ is much more easily degraded on 0.33 metalwt.\% $\mathrm{FeO}_{x} / \mathrm{TiO}_{2}$ than bare anatase. Therefore, the $\mathrm{Fe}_{2} \mathrm{O}_{3}$ active species enhance the catalyst activity for $\mathrm{H}_{2} \mathrm{O}_{2}$ photo-reduction by not only increasing the charge separation but also lowering the energy barrier for $\mathrm{H}_{2} \mathrm{O}_{2}$ reduction.

A typical reaction mechanism for the selective methane oxidation to methanol was proposed as shown in Figure 4d. Incident photons first excite the electrons from the valence band (O $2 p$ orbits) of $\mathrm{TiO}_{2}$ to the conduction band ( $\mathrm{Ti} 3 d$ orbits), leaving holes on oxygen atoms as shown by the XPS in the presence and absence of light irradiation. Due to the lower conduction band potential of iron oxide than $\mathrm{TiO}_{2}$, photogenerated electrons then transfer to the conduction band of iron oxide, ${ }^{61,62}$ which can be observed in the Fe $2 p$ XPS with and without Xenon lamp irradiation. $\mathrm{H}_{2} \mathrm{O}_{2}$ molecules are then reduced by photogenerated electrons on iron oxide and form $\cdot \mathrm{OH}$ radicals. ${ }^{63,64}$ In parallel, methane molecules react with photogenerated holes in the valence band of $\mathrm{TiO}_{2}$ to form methyl radicals. Next, methanol molecules are generated by the reaction between methyl $\left(\mathrm{CH}_{3} \cdot\right)$ and hydroxyl $(\mathrm{OH} \cdot)$ radicals, likely on iron species. ${ }^{21}$ Therefore, 
the function of the iron species is significant as it improves electron-hole separation, lowers the reduction potential of $\mathrm{H}_{2} \mathrm{O}_{2}$ and also helps avoid oxygen reduction to $\mathrm{O}_{2} \cdot \mathrm{O}_{2}{ }^{-}$can be formed on bare $\mathrm{TiO}_{2}$ and noble metal-decorated $\mathrm{TiO}_{2}$, and then oxidise methanol to $\mathrm{CO}_{2}{ }^{65}$ Thus, the selectivity for methanol is only enhanced by the iron oxides.

a

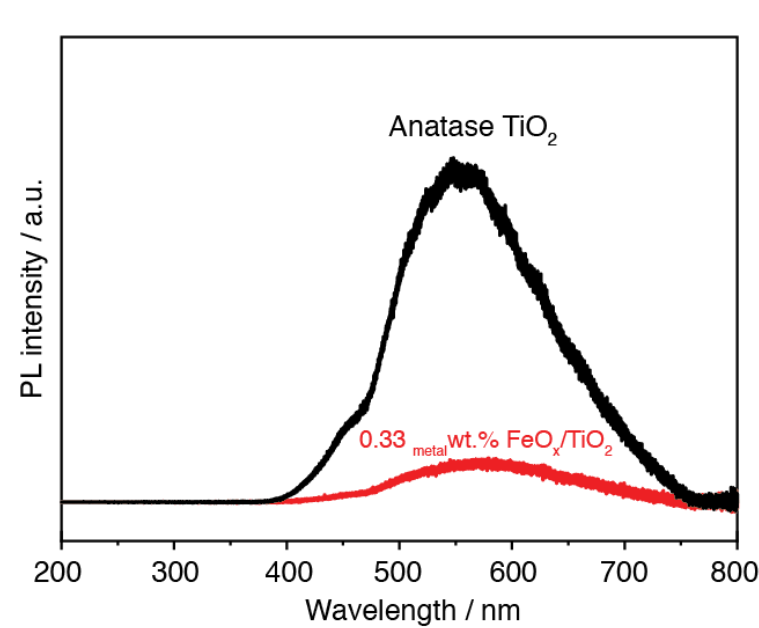

C

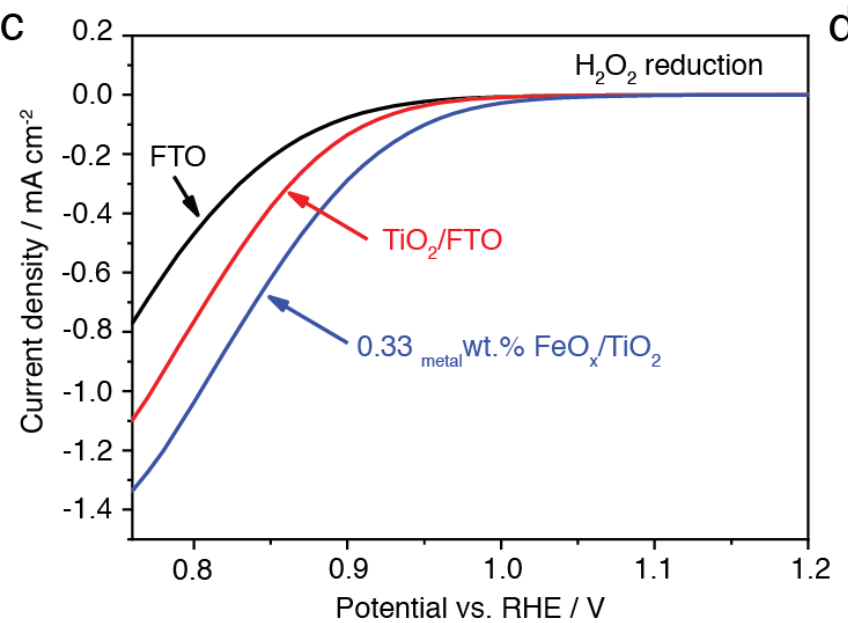

b

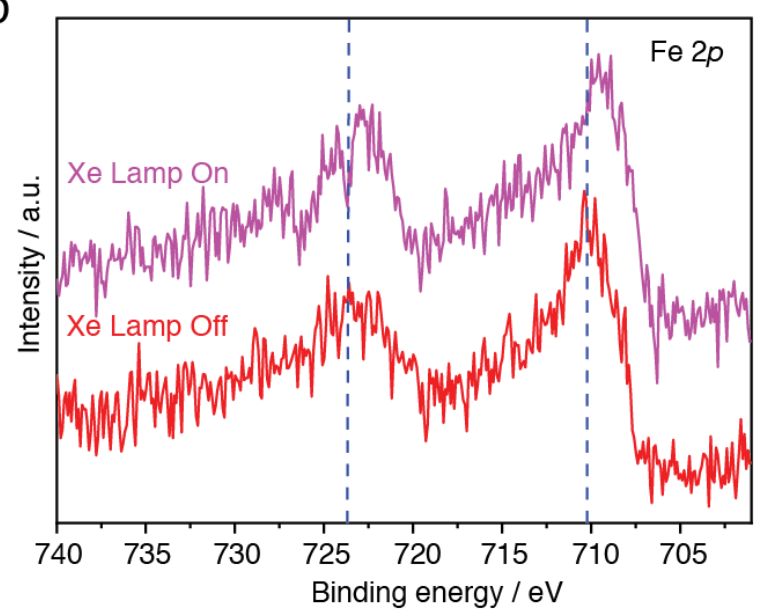

d

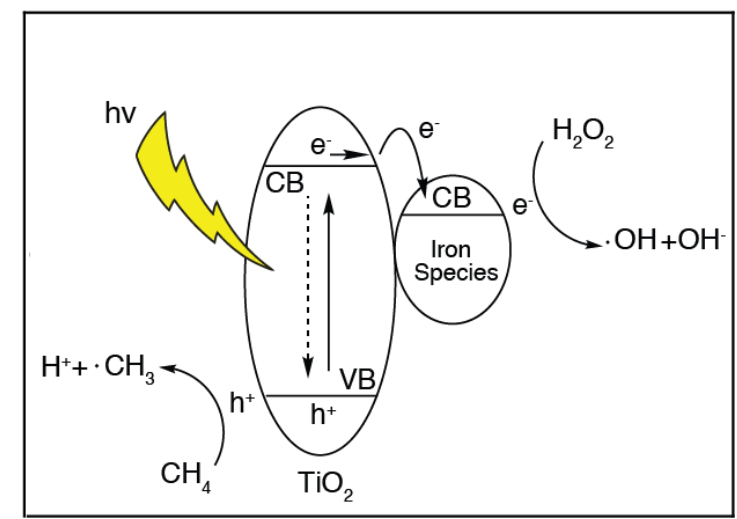

Figure 4: Chemical and physical characterisation of the $\mathrm{TiO}_{2}$ based photocatalysts. (a) $\mathrm{PL}$ spectra of anatase $\mathrm{TiO}_{2}$ and 0.33 metalwt.\% $\mathrm{FeO} \times / \mathrm{TiO}_{2}$; (b) $\mathrm{Fe} 2 \mathrm{p}$ XPS of 0.33 metalwt.\% $\mathrm{FeO} \times \mathrm{T} / \mathrm{TiO}_{2}$ in the dark and under Xe lamp irradiation; (c) FTO electrode voltammograms recorded with surface coated $\mathrm{TiO}_{2}$ and 0.33 metalwt.\% $\mathrm{FeO}_{x} / \mathrm{TiO}_{2}$ in $0.1 \mathrm{M} \mathrm{H}_{2} \mathrm{O}_{2}$ and $0.1 \mathrm{M} \mathrm{Na}_{2} \mathrm{SO}_{4}$ aqueous solution (d) and schematic of charge transfer during methane partial oxidation on 0.33 metalwt.\% $\mathrm{FeO}_{x} / \mathrm{TiO}_{2}$.

\section{Conclusion}

In summary, we have presented an effective strategy for the highly selective transformation of methane to methanol under ambient conditions and moderate light irradiation (close to one sun). Highly dispersed iron oxide species, among which also atomically dispersed species, have been successfully anchored onto $\mathrm{TiO}_{2}$. The catalyst with optimised metal loading -0.33 metalwt.\% $\mathrm{FeO}_{x} / \mathrm{TiO}_{2}$ - features both $\mathrm{FeOOH}$ and $\mathrm{Fe}_{2} \mathrm{O}_{3}$ active sites and results in nearly four 
times higher methanol production than bare $\mathrm{TiO}_{2}$. It also presents $>97 \%$ selectivity towards alcohols and yields 18 moles of methanol per mole of iron, or $1056 \mu$ moles methanol per gram of catalyst only in three hours. Recycling tests indicate good stability of the iron species decorated catalysts. Based on spectroscopic measurements and structural analysis, the superior activity of the catalyst towards methane partial oxidation under ambient conditions can be ascribed to the efficient electron transfer from $\mathrm{TiO}_{2}$ to iron species (e.g. a two fold increase in charge collection efficiency when loading of iron species), a lower overpotential for $\mathrm{H}_{2} \mathrm{O}_{2}$ reduction on iron species and supression of the oxygen reduction reaction that would shift selectivity towards $\mathrm{CO}_{2}$ instead of methanol. Such properties may be generally applied as design criteria for photocatalysts with improved activity and selectivity.

\section{Methods}

Fabrication of photocatalysts

A highly reproducible impregnation method was used to prepare modified $\mathrm{TiO} 2$ photocatalysts. In a typical experiment, a certain amount of metal chloride (e.g. $\mathrm{FeCl} 3, \mathrm{H}_{2} \mathrm{PtCl}_{6}$ ) was first dissolved in $1.5 \mathrm{~mL}$ deionised water, and then added drop wise onto $0.1 \mathrm{~g}$ of commercial pure anatase $\mathrm{TiO}_{2}$ (Millennium PC 50) under vigorous stirring. After all the water had evaporated, the mixture was immediately transferred into a high quality alumina crucible equipped with a lid and then placed inside a muff furnace in atomasphere. Next, the mixture was heated at a ramping rate of $5{ }^{\circ} \mathrm{C} / \mathrm{min}$ and finally held at $400{ }^{\circ} \mathrm{C}$ for 4 hours in the muffle furnace in atmosphere. After the product was cooled down to room temperature, the samples were then washed with water 3 times and stored for characterisation and activity test.

Characterisation

Powder X-Ray Diffraction (PXRD) measurements were taken using a Stoe StadiP diffractometer (wavelength $0.071 \mathrm{~nm}$ ). X-ray photoelectron spectroscopy (XPS) was performed on a Thermo Scientific XPS K-alpha machine using monochromatic Al-Ka radiation. Survey scans were collected in the range $0-1100 \mathrm{eV}$ (binding energy) at a pass energy of 160 eV. Synchronous illumination X-ray photoelectron spectroscopy was performed on ESCALAB 250Xi (Thermo Fisher), equipped with a $300 \mathrm{~W}$ Xe arc lamp as the illumination source. The illumination source was set to $20 \mathrm{~cm}$ from the sample and the light intensity was set to 25 $\mathrm{mW} / \mathrm{cm}^{2}$. Higher resolution scans were recorded for the main core lines at a pass energy of $20 \mathrm{eV}$. Analysis was performed on CasaXPS software. Inductively coupled plasma-atomic emission spectrometry (ICP-AES) measurements were conducted with a Varian 720 ICP-AES, axial configuration, equipped with an autosampler. Specific surface areas were measured using the BET method with $\mathrm{N}_{2}$ absorption and the data collected by a Micromeritics TriStar 
3000 gas adsorption analyser. UV-Vis absorption spectra were obtained on a Shimadzu UVVis 2550 spectrophotometer fitted with an integrating sphere. Reflectance measurements were performed on powdered samples, using a standard barium sulphate powder as a reference. The reflection measurements were converted to the absorption spectra using the Kubelka-Mulk transformation. Photoluminescence $(\mathrm{PL})$ spectra were observed on a Renishaw InVia Raman Microscope, using a $514 \mathrm{~nm}$ excitation laser, between $100-3500 \mathrm{~cm}^{-1}$ and 200 $800 \mathrm{~nm}$, respectively. The STEM measurements were performed on a $300 \mathrm{kV}$ Titan G2 60300 microscope (FEI, Eindhoven, The Netherlands) equipped with a probe Cs-corrector and a super-X EDX detector (FEI). The X-ray absorption spectroscopy spectra (XAFS) of Fe K edge $(7112 \mathrm{eV})$ were acquired at the BL14W beamline of the Shanghai Synchrotron Radiation Facility. XAFS spectra of the samples were collected at 14W of SSRF in fluorescence mode. The signals were collected with a 36-channel solid state detector. The signals of each channel were summed together to obtain one scan and five scans were merged into one spectrum to gain high-quality spectra. For samples preparation, the powder was ground into fine particles (60-80 mesh) and then pressed into $0.8 \mathrm{~cm}$ pellet $(0.4 \mathrm{~mm}$ thickness) for the measurement. To reduce the high order harmonics, a harmonic suppression mirror was used with rhodium coating. The collimated beam was tuned by the $\mathrm{Si}$ (111) double-crystal monochromators and focused by a toroidal mirror to a spot size of $<0.3 \mathrm{~mm} \times 0.3 \mathrm{~mm} .{ }^{66}$ Beside Fe foil, the FeO, $\mathrm{Fe}_{3} \mathrm{O}_{4}, \mathrm{Fe}_{2} \mathrm{O}_{3}, \mathrm{FeOOH}, \mathrm{Fe}(\mathrm{OH})_{3}$ powder were also used as the reference material. All collected spectra were processed and analysed using Athena code within Ifeffit package. For the X-ray absorption near edge structure (XANES) part, the experimental absorption coefficients as a function of energies were processed by background subtraction and normalization procedures, and reported as the normalized intensity. The extended X-ray absorption fine structure (EXAFS) oscillation was fitted according to a back-scattering equation, using FEFF models generated from crystal structure of $\mathrm{Fe}_{2} \mathrm{O}_{3}$ (space group $R \overline{3} c$ H). ${ }^{67}$ Intensity-modulated photocurrent spectroscopy (IMPS) and photovoltage spectroscopy (IMVS) measurements were conducted using a potentiostat (IVIUM technology) in a threeelectrode configuration at $\mathrm{pH}=7$. Modulated illumination (LED: ultraviolet $365 \mathrm{~nm}$ ) was provided by a ModuLightmodule (IVIUM technology).

Photocatalytic activity test

The photocatalytic activity measurement of methane oxidation were carried out in a $170 \mathrm{ml}$ custom-made batch reactor cell irradiated by a 300W Xe Lamp (Newport 67005) as shown in Supplementary Figure 29. A $710 \mathrm{~nm}$ short pass filter (Comar Optics) was installed to cut off infrared irradiation. The reaction temperature was controlled to $25^{\circ} \mathrm{C}$ with a cooling water bath. 
A magnetic stirrer was utilised to facilitate the mass transfer between the reactants and photocatalysts.

In a typical test, $10 \mathrm{mg}$ sample was first suspended and subsequently sonicated in $6 \mathrm{~mL}$ deionised water. The reactor was sealed and purged with a mixture gas of methane (BOC $20 \%$ Methane/Argon) or ${ }^{13} \mathrm{C}$ isotope labelled $\mathrm{CH}_{4}$ (Sigma, 99 atom $\%{ }^{13} \mathrm{C}$ ) and argon (BOC $99.999 \%)$ at a ratio of $1: 19$ for 30 minutes. The initial feedstock ratio was controlled by two mass flow meters (Bronkhorst EL-FLOW). Then, $2 \mathrm{mM} \mathrm{H}_{2} \mathrm{O}_{2}$ solution ( $4 \mathrm{~mL}$ ) was added into the reactor as an oxidant and then photo-irradiation started immediately.

A Varian 450-GC equipped with a methanizer, a flame ionization detector (FID) and a thermal conductivity detector (TCD) was used to analyse the products of $\mathrm{H}_{2}, \mathrm{O}_{2}, \mathrm{CO}, \mathrm{CO}_{2}$, methanol, ethanol, and further confirmed the conversion of $\mathrm{CH}_{4}$. A Shimadzu GCMS-QP2010 Plus (a gas chromatography combining with a mass spectrometer) installed with a methanizer, a FID detector and an ionizer detector was applied for further identifying all products detected by $\mathrm{GC}$, especially in the ${ }^{13} \mathrm{C}$ measurement. Furthermore, Mass spectrometry is a more sensitive technique for aldehyde and formic acid detection than FID, thus it was utilised to monitor the generation of aldehyde and formic acid.

The amount of $\mathrm{CH}_{4}$ was measured by the amount of $\mathrm{CH}_{4}$ in the headspace of the reactor. The solubility of $\mathrm{CH}_{4}$ is very low, about $22 \mathrm{~g} / \mathrm{L}_{\text {water }}$, and the total volume of water was $10 \mathrm{ml}$ in the $170 \mathrm{ml}$ reactor. ${ }^{68}$ The dissolved $\mathrm{CH}_{4}$ can be calculated as $0.014 \mu \mathrm{mol}$ based on its solubility and partial pressure, which is $0.02 \%$ of the $\mathrm{CH}_{4}$ in gaseous phase, so the conversion was calculated with respect to the amount of $\mathrm{CH}_{4}$ in gaseous phase.

The amount of alcohol was measured by the amount of methanol in the headspace of the reactor as well. According to Raoult's Law, in a sealed system, liquid and vapour phases would reach equilibrium thermodynamically under a certain temperature and pressure. The initial amount of each component (e.g. methanol) in the liquid phase can be theoretically calculated using the amount of the component detected in the gaseous phase.

Calibration for alcohols by using methanol as an example. $10 \mathrm{ml}$ aqueous solution of different concentrations of methanol was first sealed in a gas tight reactor with argon as the balance gas. Then, the solution was stirred under light irradiation for 20 minutes. $1 \mathrm{ml}$ of the headspace vapour was analysed by the GC. The calibration curve is shown in Supplementary Figure 30. This linear curve was further validated by the liquid sample analysis by a GC-MS.. This linear profile was achieved for quantities of methanol between 0 and 25 micromoles in $10 \mathrm{ml}$ aqueous solution. The methanol produced in this study was between 0 and 10 micromoles when $10 \mathrm{mg}$ of catalyst was used, well within the linear range. 


\section{Data Availability}

The data that support the plots within this paper and other findings of this study are available from the corresponding author upon reasonable request.

\section{References}

1. McFarland, E. Unconventional chemistry for unconventional natural gas. Science 338, 341-342 (2012).

2. Abbas, H. F. \& Wan Daud, W. M. A. M. a. Hydrogen production by methane decomposition: A review. Int. J. Hydrogen Energy 35, 1160-1190 (2010).

3. Ravi, M., Ranocchiari, M. \& van Bokhoven, J. A. The Direct Catalytic Oxidation of Methane to Methanol-A Critical Assessment. Angew. Chem. Int. Ed. 56, 1646416483 (2017).

4. Liu, H. et al. A review of anode catalysis in the direct methanol fuel cell. J. Power Sources 155, 95-110 (2006).

5. Periana, R. A. et al. A Mercury-Catalyzed, High-Yield System for the Oxidation of Methane to Methanol. Science 259, 340-343 (1993).

6. Periana, R. A. et al. Methanol Derivative Platinum Catalysts for the High-Yield Oxidation of Methane to a Methanol Derivative. Science 280, 560-564 (1998).

7. Palkovits, R. et al. Development of molecular and solid catalysts for the direct lowtemperature oxidation of methane to methanol. ChemSusChem 3, 277-282 (2010).

8. Zimmermann, T., Soorholtz, M., Bilke, M. \& Schüth, F. Selective Methane Oxidation Catalyzed by Platinum Salts in Oleum at Turnover Frequencies of Large-Scale Industrial Processes. J. Am. Chem. Soc. 138, 12395-12400 (2016).

9. Muehlhofer, M., Strassner, T. \& Herrmann, W. A. New catalyst systems for the catalytic conversion of methane into methanol. Angew. Chem. Int. Ed. 41, 1745-1747 (2002).

10. Vitaly L. Sushkevich, Dennis Palagin, M. R. \& J. A. van B. Selective anaerobic oxidation of methane enables direct synthesis of methanol. Science 356, 523-527 (2017).

11. Huang, W. et al. Low-Temperature Transformation of Methane to Methanol on Pd1O4 Single Sites Anchored on the Internal Surface of Microporous Silicate. Angew. Chem. Int. Ed. 55, 13441-13445 (2016).

12. Hammond, C. et al. Aqueous-phase methane oxidation over Fe-MFI zeolites; Promotion through isomorphous framework substitution. ACS Catal. 3, 1835-1844 (2013).

13. Hammond, C. et al. Direct catalytic conversion of methane to methanol in an aqueous medium by using copper-promoted Fe-ZSM-5. Angew. Chem. Int. Ed. 51, 5129-5133 (2012).

14. Sobolev, V. I., Dubkov, K. A., Panna, O. V. \& Panov, G. I. Selective oxidation of methane to methanol on a FeZSM-5 surface. Catal. Today 24, 251-252 (1995).

15. Hammond, C. et al. Elucidation and evolution of the active component within $\mathrm{Cu} / \mathrm{Fe} / \mathrm{ZSM}-5$ for catalytic methane oxidation: From synthesis to catalysis. ACS Catal. 3, 689-699 (2013).

16. Liu, C.-C., Mou, C.-Y., Yu, S. S.-F. \& Chan, S. I. Heterogeneous formulation of the 
tricopper complex for efficient catalytic conversion of methane into methanol at ambient temperature and pressure. Energy Environ. Sci. 9, 1361-1374 (2016).

17. Grundner, S. et al. Single-site trinuclear copper oxygen clusters in mordenite for selective conversion of methane to methanol. Nat. Commun. 6, 7546 (2015).

18. Ab Rahim, M. H. et al. Low temperature selective oxidation of methane to methanol using titania supported gold palladium copper catalysts. Catal. Sci. Technol. 6, 34103418 (2016).

19. Groothaert, M. H., Smeets, P. J., Sels, B. F., Jacobs, P. A. \& Schoonheydt, R. A. Selective oxidation of methane by the bis( $\mu$-oxo)dicopper core stabilized on ZSM-5 and mordenite zeolites. J. Am. Chem. Soc. 127, 1394-1395 (2005).

20. Sheppard, T., Hamill, C. D., Goguet, A., Rooney, D. W. \& Thompson, J. M. A low temperature, isothermal gas-phase system for conversion of methane to methanol over Cu-ZSM-5. Chem. Commun. 50, 11053-11055 (2014).

21. Agarwal, N. et al. Aqueous Au-Pd colloids catalyze selective $\mathrm{CH}_{4}$ oxidation to $\mathrm{CH}_{3}$ $\mathrm{OH}$ with $\mathrm{O}_{2}$ under mild conditions. Science 358, 223-227 (2017).

22. Shan, J., Li, M., Allard, L. F., Lee, S. \& Flytzani-Stephanopoulos, M. Mild oxidation of methane to methanol or acetic acid on supported isolated rhodium catalysts. Nature 551, 605-608 (2017).

23. Moniz, S. J. A., Shevlin, S. A., Martin, D. J., Guo, Z.-X. \& Tang, J. Visible-light driven heterojunction photocatalysts for water splitting - a critical review. Energy Environ. Sci. 8, 731-759 (2015).

24. Jiang, C., Moniz, S. J. A., Wang, A., Zhang, T. \& Tang, J. Photoelectrochemical devices for solar water splitting - materials and challenges. Chem. Soc. Rev. 46, 4645-4660 (2017).

25. Kong, D. et al. Recent advances in visible light-driven water oxidation and reduction in suspension systems. Mater. Today (2018). doi:10.1016/j.mattod.2018.04.009

26. Wang, $\mathrm{Y}$. et al. Mimicking Natural Photosynthesis: Solar to Renewable $\mathrm{H}_{2}$ Fuel Synthesis by Z-Scheme Water Splitting Systems. Chem. Rev. 118, 5201-5241 (2018).

27. Wang, Y. et al. Bandgap Engineering of Organic Semiconductors for Highly Efficient Photocatalytic Water Splitting. Adv. Energy Mater. 8, 1801084 (2018).

28. Jiang, C. et al. Size-controlled $\mathrm{TiO}_{2}$ nanoparticles on porous hosts for enhanced photocatalytic hydrogen production. Appl. Catal. A Gen. 521, 133-139 (2016).

29. Li, H., Shang, J., Ai, Z. \& Zhang, L. Efficient visible light nitrogen fixation with $\mathrm{BiOBr}$ nanosheets of oxygen vacancies on the exposed $\{001\}$ Facets. J. Am. Chem. Soc. 137, 6393-6399 (2015).

30. Wang, S. et al. Light-Switchable Oxygen Vacancies in Ultrafine $\mathrm{Bi}_{5} \mathrm{O}_{7} \mathrm{Br}$ Nanotubes for Boosting Solar-Driven Nitrogen Fixation in Pure Water. Adv. Mater. 29, 1701774 (2017).

31. Ward, M. D., Brazdil, J. F., Mehandru, S. P. \& Anderson, A. B. Methane photoactivation on copper molybdate. An experimental and theoretical study. J. Phys. Chem. 91, 6515-6521 (1987).

32. An, X., Li, K. \& Tang, J. $\mathrm{Cu}_{2} \mathrm{O} /$ reduced graphene oxide composites for the photocatalytic conversion of CO2. ChemSusChem 7, 1086-1093 (2014).

33. Handoko, A. D., Li, K. \& Tang, J. Recent progress in artificial photosynthesis: $\mathrm{CO}_{2}$ photoreduction to valuable chemicals in a heterogeneous system. Curr. Opin. Chem. Eng. 2, 200-206 (2013). 
34. Murcia-López, S., Villa, K., Andreu, T. \& Morante, J. R. Partial oxidation of methane to methanol using bismuth-based photocatalysts. ACS Catal. 4, 3013-3019 (2014).

35. Murcia-López, S. et al. Controlled Photocatalytic Oxidation of Methane to Methanol through Surface Modification of Beta Zeolites. ACS Catal. 7, 2878-2885 (2017).

36. Villa, K., Murcia-López, S., Andreu, T. \& Morante, J. R. Mesoporous $\mathrm{WO}_{3}$ photocatalyst for the partial oxidation of methane to methanol using electron scavengers. Appl. Catal. B Environ. 163, 150-155 (2015).

37. Chen, X. et al. Photocatalytic oxidation of methane over silver decorated zinc oxide nanocatalysts. Nat. Commun. 7, 12273 (2016).

38. Božanić, D. K., Luyt, A. S., Trandafilović, L. V. \& Djoković, V. Glycogen and gold nanoparticle bioconjugates: controlled plasmon resonance via glycogen-induced nanoparticle aggregation. RSC Adv. 3, 8705 (2013).

39. Wu, P., Huang, Y., Kang, L., Wu, M. \& Wang, Y. Multisource synergistic electrocatalytic oxidation effect of strongly coupled $\mathrm{PdM}(\mathrm{M}=\mathrm{Sn}, \mathrm{Pb}) / \mathrm{N}$-doped graphene nanocomposite on small organic molecules. Sci. Rep. 5, 14173 (2015).

40. Jian-Dong, X. et al. Improvement of Adsorptive Separation Performance for $\mathrm{C}_{2} \mathrm{H}_{4}$ /C2H6 Mixture by $\mathrm{CeO}_{2}$ Promoted $\mathrm{CuCl} /$ Activated Carbon Adsorbents. Acta Phys. Chim. Sin. 31, 2158-2164 (2015).

41. Yang, P. et al. Ultrafast-charging supercapacitors based on corn-like titanium nitride nanostructures. Adv. Sci. 3, 1500299 (2015).

42. Abazović, N. D. et al. Synthesis and characterization of rutile $\mathrm{TiO}_{2}$ nanopowders doped with iron ions. Nanoscale Res. Lett. 4, 518-525 (2009).

43. Vinayan, B. P. \& Ramaprabhu, S. Platinum-TM (TM = Fe, Co) alloy nanoparticles dispersed nitrogen doped (reduced graphene oxide-multiwalled carbon nanotube) hybrid structure cathode electrocatalysts for high performance PEMFC applications. Nanoscale 5, 5109 (2013).

44. Kanakaraju, D., Kockler, J., Motti, C. A., Glass, B. D. \& Oelgemöller, M. Titanium dioxide/zeolite integrated photocatalytic adsorbents for the degradation of amoxicillin. Appl. Catal. B Environ. 166-167, 45-55 (2015).

45. Xu, Z. et al. Sulfate functionalized $\mathrm{Fe}_{2} \mathrm{O}_{3}$ nanoparticles on $\mathrm{TiO}_{2}$ nanotube as efficient visible light-active photo-fenton catalyst. Ind. Eng. Chem. Res. 54, 4593-4602 (2015).

46. Qiu, B., Xing, M. \& Zhang, J. Stöber-like method to synthesize ultralight, porous, stretchable $\mathrm{Fe}_{2} \mathrm{O}_{3}$ /graphene aerogels for excellent performance in photo-Fenton reaction and electrochemical capacitors. J. Mater. Chem. A 3, 12820-12827 (2015).

47. López-Martín, Á., Caballero, A. \& Colón, G. Photochemical methane partial oxidation to methanol assisted by $\mathrm{H}_{2} \mathrm{O}_{2}$. J. Photochem. Photobiol. A Chem. 349, 216-223 (2017).

48. Chen, L. C., Yu, Z. \& Hiraoka, K. Vapor phase detection of hydrogen peroxide with ambient sampling chemi/chemical ionization mass spectrometry. Anal. Methods 2, 897 (2010).

49. Grossnickle, J. A. et al. Particle and recycling control in translation, confinement, and sustainment upgrade. Phys. Plasmas 17, 032506 (2010).

50. Liu, J. et al. Designed synthesis of $\mathrm{TiO}_{2}$-modified iron oxides on/among carbon nanotubes as a superior lithium-ion storage material. J. Mater. Chem. A 2, 1137211381 (2014).

51. McIntyre, N. S. \& Zetaruk, D. G. X-ray Photoelectron Spectroscopic Studies of Iron Oxides. Anal. Chem. 49, 1521-1529 (1977). 
52. Kuzmin, A. \& Chaboy, J. EXAFS and XANES analysis of oxides at the nanoscale. IUCrJ 1, 571-589 (2014).

53. Wang, Y. et al. Linker-controlled polymeric photocatalyst for highly efficient hydrogen evolution from water. Energy Environ. Sci. 10, 1643-1651 (2017).

54. Xie, J. et al. Efficient Visible Light-Driven Water Oxidation and Proton Reduction by an Ordered Covalent Triazine-Based Framework. Energy Environ. Sci. 11, 1617-1624 (2018).

55. Peter, L. Kinetics and Mechanisms of Light-Driven Reactions at Semiconductor Electrodes: Principles and Techniques. Photoelectrochemical Water Splitting: Materials, Processes and Architectures (The Royal Society of Chemistry, 2013).

56. Zhang, C. et al. Photoelectrochemical analysis of the dyed $\mathrm{TiO}_{2} /$ electrolyte interface in long-term stability of dye-sensitized solar cells. J. Phys. Chem. C 116, 1980719813 (2012).

57. Ruan, Q. et al. A Nanojunction Polymer Photoelectrode for Efficient Charge Transport and Separation. Angew. Chem. Int. Ed. 56, 8221-8225 (2017).

58. Jiang, W. et al. Oxygen-doped carbon nitride aerogel: A self-supported photocatalyst for solar-to-chemical energy conversion. Appl. Catal. B Environ. 236, 428-435 (2018).

59. Wu, Z. et al. Characterization and activity of $\mathrm{Pd}$-modified $\mathrm{TiO}_{2}$ catalysts for photocatalytic oxidation of NO in gas phase. J. Hazard. Mater. 164, 542-548 (2009).

60. Ohtsu, N., Masahashi, N., Mizukoshi, Y. \& Wagatsuma, K. Hydrocarbon decomposition on a hydrophilic $\mathrm{TiO}_{2}$ surface by UV irradiation: Spectral and quantitative analysis using in-situ XPS technique. Langmuir 25, 11586-11591 (2009).

61. Moniz, S. J. A., Shevlin, S. A., An, X., Guo, Z. X. \& Tang, J. $\mathrm{Fe}_{2} \mathrm{O}_{3}-\mathrm{TiO}_{2}$ nanocomposites for enhanced charge separation and photocatalytic activity. Chem. A Eur. J. 20, 15571-15579 (2014).

62. Kudo, A. \& Miseki, Y. Heterogeneous photocatalyst materials for water splitting. Chem. Soc. Rev. 38, 253-278 (2009).

63. Liu, T., Li, X., Yuan, X., Wang, Y. \& Li, F. Enhanced visible-light photocatalytic activity of a $\mathrm{TiO}_{2}$ hydrosol assisted by $\mathrm{H}_{2} \mathrm{O}_{2}$ : Surface complexation and kinetic modeling. $J$. Mol. Catal. A Chem. 414, 122-129 (2016).

64. Da Silva, A. C. et al. Improved photocatalytic activity of $\delta-\mathrm{FeOOH}$ by using $\mathrm{H}_{2} \mathrm{O}_{2}$ as an electron acceptor. J. Photochem. Photobiol. A Chem. 332, 54-59 (2017).

65. Kumar, S. G. \& Devi, L. G. Review on modified $\mathrm{TiO}_{2}$ photocatalysis under UV/visible light: Selected results and related mechanisms on interfacial charge carrier transfer dynamics. J. Phys. Chem. A 115, 13211-13241 (2011).

66. Ravel, B. \& Newville, M. ATHENA, ARTEMIS, HEPHAESTUS: Data analysis for X-ray absorption spectroscopy using IFEFFIT. J. Synchrotron Radiat. 12, 537-541 (2005).

67. Yu, H. S. et al. The XAFS beamline of SSRF. Nucl. Sci. Tech. 26, 050102 (2015).

68. Dean, J. A. LANGE'S HANDBOOK OF CHEMISTRY-Fiftenth Edition. McGRAW-HILL, INC.

\section{Acknowledgement}

We thank the financial support from UK EPSRC (EP/N009533/1), Royal Society-Newton Advanced Fellowship grant (NA170422), the Leverhulme Trust (RPG-2017-122), the Natural Science Foundation of China (21725301, 91645115, 21473003, 21821004, 21573264, 
21622310, 21603247, 21703266), National Key R\&D Program of China (2017YFB0602200), China Scholarship Council and First UCL-PKU Strategic Partner Funds. The ICP tests were conducted in UCL Earth Sciences by Ms Becki Belgrave. The XAS experiments were carried out at the Shanghai Synchrotron Radiation Facility (SSRF) and Beijing Synchrotron Radiation Facility (BSRF). We all are thankful to Dr Christopher Windle at UCL for his valuable discussion and thorough check.

\section{Author contribution}

J.X. conducted the catalysts preparation, the activity tests and sample characterisations by XPS, PL and SEM; R.J. analysed and discussed the results of TEM, XAFS and XPS with and without Xe lamp irradiation. A.L. carried out the STEM. Y.B. and Y.Z. analysed the sample by XPS with and without Xe lamp irradiation. Q.R. collected XRD patterns and carried out the IMPS, IMVS measurements and $\mathrm{H}_{2} \mathrm{O}_{2}$ reduction in a three-electrode cell. Y.D. conducted the EXAFS and XANES experiments. S.Y. and G.S. contributed to the discussion of XAFS results and reaction mechanism. J.T. and D. M. designed the entire project and J.T. also supervised the progress of the project. The manuscript was written through collective contributions of all authors. They have given their approval of the final version of the manuscript.

\section{Competing Interests}

The authors declare no competing interests. 